\title{
Transitioning Towards New Ways of Working: Do Job Demands, Job Resources, Burnout, and Engagement Change?
}

Psychological Reports 2018, Vol. I2I(4) 736-766 (C) The Author(s) 2017 Reprints and permissions: sagepub.com/journalsPermissions.nav DOI: 10.1 I 177/0033294|I7740I34 journals.sagepub.com/home/prx

@SAGE

\section{Elianne F. Van Steenbergen}

Department of Social, Health and Organizational Psychology, Utrecht University, Utrecht, the Netherlands

\section{Cilia van der Ven}

IKEA, Amersfoort, the Netherlands

\section{Maria C. W. Peeters and Toon W. Taris}

Department of Social, Health and Organizational Psychology, Utrecht University, Utrecht, the Netherlands

\begin{abstract}
Purpose: The purpose of this study was to investigate the effects of a mandatory transition to New Ways of Working (NWW) on employees' job demands (i.e., mental demands, workload, and task ambiguity), job resources (i.e., autonomy, supervisor support, coworker support, and possibilities for development), and their levels of burnout and work engagement. Additionally, it was investigated whether the effects of the transition depended on employees' personal resources (Psychological Capital-PsyCap).

Design/methodology/approach: We investigated an organization in transition. In three waves (one before and two after the transition), data were collected via online surveys among 126 employees of a large Dutch provider of financial services. Findings: NWW were beneficial in reducing mental demands and workload and did not harm the relationships with supervisor and coworkers. However, autonomy and possibilities for professional development decreased. Burnout and work engagement remained stable over time. The effects of the transition did not depend on employees' PsyCap.
\end{abstract}

\section{Corresponding Author:}

Elianne F. Van Steenbergen, Department of Social, Health and Organizational Psychology, Utrecht University, P.O. Box 80.140, Utrecht NL-3508 TC, the Netherlands.

Email: E.F.vanSteenbergen@uu.nl 
Implications: NWW have received a very positive popular press. Scientific evidence for its beneficial and/or adverse effects on worker well-being can help organizations making an informed decision when considering NWW. Moreover, this can help to develop targeted interventions that alleviate the negative consequences (e.g., paying extra attention to professional development).

Originality/value: This is one of the first longitudinal studies in which employees were followed who transitioned to NWW. Building on the Job Demands-Resources model, this study provides a comprehensive picture of the effects of NWW.

\section{Keywords}

New Ways of Working, transition, job demands-resources, longitudinal

\section{Introduction}

Over the past few decades, the organization of the Western labor market has changed fundamentally. Globalization, increased competition, and the shift from a manufacturing industry to services urge organizations to be flexible and to rapidly adapt to changes in consumer needs (Korver, 2006). In response, an increasing number of organizations introduce more flexible work arrangements or New Ways of Working (NWW). NWW have three key characteristics (Baarne, Houtkamp, \& Knotter, 2010; Ten Brummelhuis, Bakker, Hetland, \& Keulemans, 2012). First, the timing of work is more flexible as employees get more autonomy in deciding when they work. Second, employees can decide where they work, including the office, home, and during commuting time (e.g., in the train). At the office, instead of fixed work spaces, plain office spaces are provided, which are suitable for every employee (Kelliher \& Anderson, 2008). Third, NWW are facilitated by information technology, such as e-mail, smartphones, and videoconferences. In sum, NWW can be defined as a work design in which employees can control the timing and place of their work, while being supported by electronic communication (Ten Brummelhuis et al., 2012).

Although relatively little empirical research has been done on the concept of NWW as a whole, a sizable body of research exists on its components: flexible work schedules (the when aspect) and telecommuting (the where aspect, supported by electronic communication). However, this previous research reveals intense scholarly debate (Virick, DaSilva, \& Arrington, 2010). Gajendran and Harrison (2007) even mentioned a telecommuting paradox, with many scholars advertising potential benefits of telecommuting that are incompatible with the potential disadvantages mentioned by others. For example, whereas telecommuting is touted as a means for increasing employees' autonomy, with positive consequences for job satisfaction (Gajendran \& Harrison, 2007), other researchers have emphasized its potential damaging effect on social relations (Golden, 2006), which should negatively impact job satisfaction. Similarly, Ter Hoeven, van Zoonen, and Fonner (2016) speak of the paradox of technology 
because electronic communication is both thought to increase employees' wellbeing (e.g., via more efficiency) as well as decrease their well-being (e.g., via more interruptions).

Empirical findings do not reveal a clear picture either. On the one hand, NWW have been related to beneficial outcomes, such as enhanced worker morale (Brownson, 2004), increased productivity, job satisfaction and autonomy, and reduced turnover intentions and role stress (Gajendran \& Harrison, 2007). On the other hand, research has reported disadvantages for employees, such as a deterioration of relationships with coworkers and supervisors (Golden, 2006; Sardeshmukh, Sharma, \& Golden, 2012), negative emotions such as loneliness (Mann \& Holdsworth, 2003), and professional isolation and hampered career opportunities (Cooper \& Kurland, 2002; Golden, Veiga, \& Dino, 2008).

To date, there are at least four important shortcomings in the literature on NWW. Firstly, almost all studies were cross-sectional, meaning that no causal inferences on the effects of NWW across time can be drawn (Taris, De Lange, \& Kompier, 2010). Secondly, many studies lack a theoretical framework for studying NWW. Moreover, these studies generally focused only on a limited number of job demands or resources. This implies that, as yet, no overall picture of the effects of NWW on various employee outcomes is available. Thirdly, few studies have examined the relationship between NWW and more distal employee outcomes such as burnout and work engagement (for exceptions, see Ten Brummelhuis et al., 2012; Ter Hoeven et al., 2016), whereas these concepts are linked to important health and organizational outcomes. Burnout relates to higher turnover intentions, health issues such as cardiovascular problems (Schaufeli \& Bakker, 2004), and sickness absenteeism (Schaufeli, Bakker, \& Van Rhenen, 2009). In addition, negative effects of burnout on job performance have been found (Wright \& Bonett, 1997). Conversely, engaged employees are less frequently ill (Schaufeli et al., 2009) and perform better at work (Salanova, Agut, \& Peiró, 2005). Thus, potential changes in burnout and work engagement due to a transition to NWW may have vital consequences for employees' health and performance. Finally, individual differences have hardly been taken into account. Hence, it is unknown whether the effects of NWW are the same for all employees. Previous findings have underlined the importance of individual differences in effectively coping with organizational change processes (Van den Heuvel, Demerouti, Bakker, \& Schaufeli, 2010), suggesting that some employees are more capable of making the transition to NWW than others. However, to date, this issue has not been explored.

The present research was designed to fill these voids. The first aim of this research was to examine how a mandatory transition to NWW affected job characteristics and employees' burnout and work engagement. In the Dutch organization under study, all employees had to transition to NWW. In order to examine short- as well as long-term effects, the consequences of NWW were 
investigated through a longitudinal design with three time periods (T0: One month prior to the transition; T1: Three months after the transition; T2: One year after the transition). We examined whether the transition from a traditional work mode to NWW altered various experienced job demands, job resources, burnout, and work engagement over time, in order to obtain a thorough understanding of its impact. The second aim of this research was to examine the role of employees' psychological capital (PsyCap, i.e., the combination of workrelated self-efficacy, optimism, hope, and resilience; Luthans, Avolio, Avey, \& Norman, 2007). The relevance of this concept for various individual and organizational outcomes such as employees' well-being and performance has been demonstrated in prior studies (Luthans et al., 2007; Luthans, Norman, Avolio, \& Avey, 2008). The present study examined whether higher PsyCap (as measured before the transition) moderated the effects of transition to NWW. For example, did possessing higher PsyCap help employees to experience less burnout or more work engagement at T1 and T2? The current approach not only contributes to the literature by showing whether a transition to NWW affects burnout and work engagement but also how these effects emerge by examining changes in important predictors (i.e., job demands and resources) of these outcome variables. This sheds light on the underlying mechanism of the effects of NWW and the question whether the NWW paradox really exists. This study might also reveal systematic differences between employees as a function of their personal resources. A deeper understanding of the consequences of NWW on various types of employees provides practical input for human resource management to support sustainable employability in the context of this new work modality.

\section{The effects of NWW on job characteristics}

The Job Demands-Resources (JD-R) model (Demerouti, Bakker, Nachreiner, \& Schaufeli, 2001) presents a comprehensive theoretical framework for studying the effects of NWW on job characteristics such as work overload and social support, which in turn affect employees' well-being (Demerouti, Derks, Ten Brummelhuis, \& Bakker, 2014). One of its core assumptions is that two distinctive processes contribute to job stress and motivation (Bakker \& Demerouti, 2007). The first is a depletion process in which high job demands (such as high work load) cause strain for employees, depleting employees' mental and physical energy resources, which can lead to burnout and other related health problems. The second is a motivational process, in which job resources such as coworker support lead to work engagement and better job performance (Bakker \& Demerouti, 2007). In addition, job resources can foster personal growth and development (Schaufeli \& Bakker, 2004). Job resources not only play a major role in stimulating work engagement, but previous research has also shown their potential buffering effect against high job demands (Bakker, Demerouti, \& 
Euwema, 2005). It is known that alterations in work design may entail significant changes in job demands and resources (Hackman, Pearce, \& Wolfe, 1978). As such, changes in job characteristics may have consequences for employees' burnout and work engagement (Bakker \& Demerouti, 2007).

So far, little attention has been paid to the effects of NWW on job demands and resources. Because NWW entails changes in the "when," "where," and "how" elements of work, NWW usually entail an increased sense of freedom in managing one's own time, decreased commuting time, an increase in working from home, the introduction of result-oriented evaluations, and a reduction of face-to-face interactions with coworkers (Demerouti et al., 2014; Ten Brummelhuis et al., 2012). These changes are bound to alter employee perceptions of job practices and working relationships, thereby influencing their job demands and job resources (Demerouti et al., 2014; Sardeshmukh et al., 2012). In the present study, we included the following job demands: mental demands, workload, and task ambiguity. With respect to job resources, autonomy, supervisor support, coworker support, and possibilities for professional development were included. These job characteristics emerged from previous research as key predictors of employee well-being (Schaufeli \& Taris, 2014, for an overview), and it was therefore considered important to examine their potential impact in the context of NWW as well Below, we describe our hypotheses, which are also presented in Figure 1.

Changes in job demands. Prior studies have shown that enabling employees to manage their own working hours, choose their work location, and organize their tasks with reduced supervisory control increases employees' experienced autonomy (Bailey \& Kurland, 2002; Mann, Varey, \& Button, 2000). Employees may choose a different timing or location of their work, contingent on the degree to which particular tasks are demanding. For instance, when tasks require a high level of concentration, employees may choose to perform them at a set time at home with minimal interruptions by colleagues or family members. The present study argues that this increased autonomy in choosing optimal working conditions should reduce the extent to which employees experience their job as mentally demanding. In addition, NWW have been found to relate to more efficient communication (Ten Brummelhuis et al., 2012; Ter Hoeven, 2016), which can result in less experienced workload. Furthermore, NWW save commuting time and will therefore decrease the stress associated with commuting. Moreover, the time that is saved may be used more effectively to deal with work (or family) tasks at hand (Golden, Veiga, \& Simsek, 2006; Montreuil \& Lippel, 2003), which should further reduce employees' feelings of time pressure and workload (Sardeshmukh et al., 2012).

On the other hand, the increased flexibility and the freedom associated with organizing one's own time and job practices under diminished supervisory control may affect the clarity of tasks. New workers report social and professional 


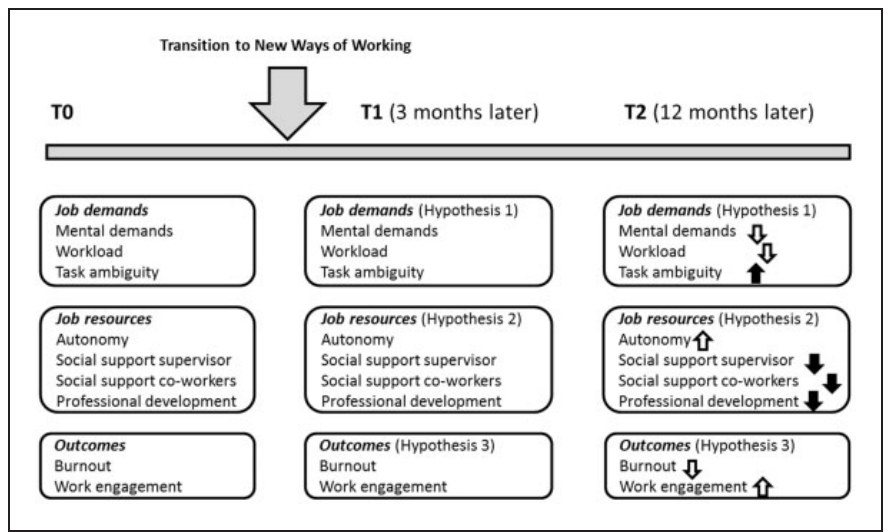

Figure I. Hypothesized changes in job demands, job resources, and outcomes after transitioning to New Ways of Working. Note: All changes are expected at TI as well as T2. An upward arrow means an increase; a downward arrow means a decreased. Black means a detrimental change, and white means a beneficial change.

isolation, reduced feedback, and lack of support from supervisors and colleagues (Cooper \& Kurland, 2002; Golden et al., 2008; Mann et al., 2000), which makes it more difficult to obtain the necessary information to perform well at the job. Sardeshmukh et al. (2012) found that the more employees telecommuted, the less clear it was for them what was expected from them by their supervisors or coworkers (see Figure 1). Therefore, we predict that:

Hypothesis 1a: In both the short and the long term, a transition to NWW involves a decrease in mental demands and workload.

Hypothesis 1b: In both the short and the long term, a transition to NWW involves an increase in task ambiguity.

Changes in job resources. NWW are assumed to lead to increased control over job practices and working times (Bailey \& Kurland, 2002; Mann et al., 2000). There is strong evidence in the literature for the importance of feeling in control over one's own tasks and personal life for well-being. For example, Gajendran and Harrison's (2007) meta-analysis revealed that the beneficial effects of telecommuting were mediated by perceived autonomy.

NWW generally also go hand in hand with less face-to-face contact. Two recent studies suggest that this does not prevent coworkers from reaching each other for practical work matters, as evidenced by increased reports of efficient (effortless, functional, and timely) communication and easy accessibility for 
coworkers (Ten Brummelhuis et al., 2012; Ter Hoeven et al., 2016). On the other hand, it may be harder to establish higher level social contact, as evidenced by studies showing that NWW relate to adverse outcomes such as lessened support from supervisors and coworkers and social and professional isolation (Cooper \& Kurland, 2002; Golden et al., 2008). Often, Daft and Lengel's (1986) Media Richness Theory is being used to account for these adverse effects (e.g., Golden et al., 2008). According to this theory, face-to-face interactions are the richest form of communication. Communicating by other media such as e-mail or telephone provides fewer social cues, which can in turn lead to misunderstandings, decreased feelings of belonging, and weakened collaboration. As NWW reduce the frequency of face-to-face interactions, having small talk, and simply "hanging out" together, there are reduced opportunities to give and receive support (Demerouti et al., 2014). Furthermore, previous research showed that NWW might decrease career development by reducing employees' access to social networks and learning opportunities (Cooper \& Kurland, 2002; Mann et al., 2000). Therefore, we predict that NWW increase perceived autonomy and decrease supervisor support, coworker support, and possibilities for professional development (see Figure 1).

Hypothesis 2a: In both the short and the long term, a transition to NWW involves an increase in autonomy.

Hypothesis 2b: In both the short and the long term, a transition to NWW involves a decrease in supervisor support, coworker support and possibilities for professional development.

\section{Individual outcomes: Burnout and work engagement}

Consistent with the JD-R model, empirical studies have shown that job demands are the most consistent predictors of burnout, whereas job resources are the most important predictors of work engagement (Schaufeli \& Taris, 2014, for a review). Furthermore, job resources have been found to buffer the adverse effects of high job demands, thus helping to protect employees against developing burnout (Bakker et al., 2005). In the present study, one job demand (task ambiguity) is predicted to increase, but two other job demands (workload and mental demands) are predicted to decrease. Moreover, autonomy - which is predicted to increase - can buffer negative effects of job demands on burnout. In sum, these alterations in job demands and autonomy should have a beneficial effect on levels of burnout (see Figure 1). Thus, based on the JD-R model, it is predicted that:

Hypothesis $3 a$ : In both the short and the long term, a transition to NWW involves a decrease in burnout. 
Gajendran and Harrison (2007) concluded that enhanced autonomy was one of the most powerful underlying mechanisms that accounted for the favorable impact of telecommuting on outcomes such as heightened job satisfaction and decreased role stress. Autonomy is assumed to affect employees' intrinsic motivation by fulfilling the basic human need of being in control over one's life (DeCharms, 1968), and also their extrinsic motivation through the accomplishment of goals (Bakker \& Demerouti, 2007). In the present study, the increase in autonomy is predicted to have a positive effect on employee work engagement. Moreover, even though a decline in three job resources (i.e., supervisor support, coworker support, and possibilities for professional development) is hypothesized, an increase in autonomy can help employees to find ways to cope with these adverse consequences. Thus, as a result of the transition to NWW, we expect work engagement to increase. This is consistent with the findings of a large study of Peters, Poutsma, Van der Heijden, Bakker, and De Bruijn (2014), comprising employees and their managers across 89 job categories in 30 organizations. This study showed that employees experienced more absorption, work enjoyment, and intrinsic motivation when teleworking constituted a structural part of their weekly work routines (that is, when they work from home at least one day per week). On a more micro-level, the diary study of Ten Brummelhuis et al. (2012) among employees of a telecompany confirmed the positive effects of NWW. Their study showed that daily use of NWW was positively related to daily work engagement (see Figure 1). Therefore, it is predicted that:

Hypothesis $3 b$ : In both the short and the long term, a transition to NWW involves an increase in work engagement.

\section{Individual resources: Psychological capital}

A further aim of the present study is to examine whether the effects of a transition to NWW are contingent upon employees' PsyCap (Luthans et al., 2007). PsyCap encompasses four personal resources, namely (1) self-efficacy (i.e., having confidence to take on and put in the necessary effort to succeed at challenging tasks), (2) optimism (making positive attributions about succeeding now and in the future), (3) hope (persevering toward goals and, when necessary, redirecting paths to goals in order to succeed), and (4) resilience (i.e., when beset by problems and adversity, sustaining and bouncing back and even beyond to attain success) (Luthans et al., 2007, p. 3).

Contrary to personality characteristics which are mostly stable over time, personal resources can be trained. Several studies have indicated that PsyCap' levels can be increased through microinterventions and e-coaching modules (Luthans, Avey, Avolio, Norman, \& Combs, 2006; Luthans, Avey, \& Patera, 2008). This suggests that PsyCap can be an effective "tool" for organizations to 
support employees in the face of organizational change. In line with this, Van den Heuvel et al. (2010) argued that employees with more personal resources can handle organizational change processes more easily, because these resources allow employees to actively shape their own job practices and work environment.

Avey, Luthans, Smith, and Palmer (2010) found that PsyCap predicts employee well-being over time. A review of the existing literature on PsyCap (Newman, Ucbasaran, Zhu, \& Hirst, 2014) confirms the positive role of PsyCap for employee well-being. In addition, the review also taps on the moderating role of PsyCap and illustrates that PsyCap has indeed the ability to buffer negative effects of stressful working conditions. In addition, several studies looking at related individual resources such as self-efficacy and self-esteem also suggest that these moderate the associations between job demands on the one hand and organizational and health outcomes on the other. For instance, Van Yperen and Snijders (2000) found that high job demands were associated with adverse health outcomes, particularly when employees had low scores on self-efficacy.

Thus, the transition to NWW could have a differential impact on employees with higher or lower levels of PsyCap, in that employees with higher levels of PsyCap are expected to be more capable of making the transition. Therefore, we propose the following moderation effects for Hypotheses 1a-3b:

Hypothesis 4a: The beneficial effects of the transition (i.e., decreases in the job demands workload and mental demands, a decrease in burnout; an increase in the job resource autonomy and an increase in work engagement) are stronger for employees with higher PsyCap than for employees with lower levels of PsyCap.

Hypothesis 4b: The adverse effects of the transition (i.e., an increase in the job demand task ambiguity, and decreases in the job resources supervisor support, coworker support, and opportunities for professional development) are weaker for employees with higher PsyCap than for employees with lower levels of PsyCap.

\section{Method}

\section{Organizational context and procedure}

The data for this study were obtained from employees of a large Dutch financial services provider. One of its offices had planned a transition to NWW, which provided a unique opportunity to examine the consequences of a transition to NWW using a longitudinal design. All employees of this office were knowledge workers who had to transition to the new building and had to work according to "the new way of working." That is why we label this transition as mandatory. The Human Resources department carefully planned and organized the transition. New working routines were documented and well communicated to 
managers and employees, via face-to-face as well as digital communication methods.

Consistent with the definition of NWW, three main organizational changes were implemented. Firstly, employees were allowed to organize their own working hours to a great extent. Secondly, employees were allowed to work from home or from another location, and did not have their own office space or desk anymore, but instead could sit at any vacant desk in an open office space ("flexible office spaces"). The HR department made sure there were enough desks available, even on busy days. The new building also offered so-called "activity-related workspaces" (e.g., concentration rooms, meeting rooms) which employees could use depending on the nature of their work activities. Thirdly, this all was facilitated by information technology as employees were provided with personal laptops and smart phones with which they could connect with colleagues and access work materials.

For the present study, three waves of data were collected via online surveys between September 2012 and October 2013. The first survey (T0) was administered one month prior to the transition. To tap both possible short- and long-term effects of the transition, the second survey (T1) was conducted three months after the transition and the third wave of data (T2) one year after the transition. To date, there is no established framework that specifies how often and when the effects of a particular intervention are best assessed. We therefore relied on frequently used rules of thumb saying that, if the speed of development of the process under study is unknown, multiple waves should be taken (i.e., to tap both possible short and long-term effects), and that a one-year time lag is a safe study interval as this means that seasonal fluctuations in-say-workload are controlled for (De Bloom, Kompier, Geurts, Taris, \& Sonnentag, 2009; Taris, 2000). Conveniently, these timeframes also corresponded with how the organization aimed to measure both the short- and the long-term effects. For all three waves of data, an online survey was sent via e-mail. To match the three data waves, participants were asked to generate their own unique personal code that remained unknown to the researchers. This code was made on the basis of their day and month of birth (four characters), the first letter of their mother's first name, and the first letter of their father's first name (two additional characters).

\section{Participants}

Of the 212 eligible participants contacted (i.e., all employees working in the office implementing NWW), 164 employees completed the first questionnaire (T0; 77.4\% response rate). The response rate of the first follow-up wave (T1) was $85.7 \%$, and the second follow-up wave (T2) had a 84.8\% response rate. Participants were only included if they had provided data for all three study waves $(N=126$ employees, i.e., $59.4 \%$ of the initial group of 
participants). The participants were on average 39.5 years old $(S D=8.7)$; $65.1 \%$ was female; $51.6 \%$ had received higher education and a further $43.7 \%$ had received intermediate education. The average job tenure was 5.3 years $(S D=5.4)$ and the average organizational tenure was 14.3 years $(S D=9.7)$. Participants were contracted to work for on average 31.8 hours per week $(S D=5.8)$.

\section{Measures}

New ways of working. In order to check whether employees really worked according to the new way of working, we assessed NWW at T0, T1, and T2 using five items. These items were developed in collaboration with the organization, on the basis of an interview with the HR manager who was responsible for the enrolment of NWW and written materials on the organization's approach of NWW. These items were (a) "I decide for myself where (office, home, elsewhere) and when I work," (b) "I use information technology (e.g., smartphone, laptop), so I can work at any chosen location or time," (c) "I regularly work remotely with my colleagues and partners," (d) "In our office, I work in an 'activity-related' manner (e.g., using spaces for concentration, communication, meetings)," and (e) "I do not have my own personal desk (flex-desk concept)" $(1=$ totally disagree, $7=$ totally agree). The Cronbach's alpha coefficients were $.56\left(\mathrm{NWW}_{\mathrm{T} 0}\right), .84\left(\mathrm{NWW}_{\mathrm{T} 1}\right)$, and $.83\left(\mathrm{NWW}_{\mathrm{T} 2}\right)$, respectively. The low reliability at $\mathrm{T} 0$ is probably caused by the fact that at $\mathrm{T} 0$, employees were not yet working according to the principles of the NWW concept. Additionally, to capture the extent to which individuals adopted NWW, we created a $N W W$ adoption variable, by subtracting NWW T0, from the mean of NWW T1 and T2: $(M \mathrm{~T} 1, \mathrm{~T} 2)-\mathrm{T} 0$.

Job demands. Mental demands were measured with four items developed by Van Veldhoven and Meijman (1994); for instance, "My work requires a high level of concentration" $(1=$ never, $5=$ always $)$. The Cronbach's alpha coefficients were $.77(\mathrm{~T} 0), .80(\mathrm{~T} 1)$, and $.80(\mathrm{~T} 2)$, respectively. Workload was measured with three items from the Dutch version (Furda, 1995) of Karasek's (1985) job content instrument; see also Bakker, Demerouti, Taris, Schaufeli, and Schreurs (2003). A sample item is: "I have to work very fast" $(1=$ never, $5=$ always $)$. The reliabilities were $.86(\mathrm{~T} 0), .87(\mathrm{~T} 1)$, and .85 (T2), respectively. Task ambiguity was measured using four items taken from Van Veldhoven and Meijman (1994), including "Do you know what others at work expect of you?" $(1=$ always, $5=$ never $)$. A higher score means less ambiguity. The reliability coefficients were .86 (T0), .88 (T1), and .88 (T2), respectively.

Job resources. Autonomy was measured using a three-item scale (Bakker, Demerouti, \& Verbeke, 2004), based on Karasek's (1985) job content 
instrument, e.g., "Can you decide for yourself how you execute your work" $(1=$ never, $5=$ always $)$. The reliability coefficients were .77 (T0), .83 (T1), and .84 (T2). Coworker support was assessed with three items developed by Van Veldhoven and Meijman (1994) including "Can you ask your colleagues for help if necessary?" ( 1 =never, $5=$ always; alpha coefficients were .83 (T0), .81 (T1), and.85 (T2)). Supervisor support was assessed with three parallel items, this time referring to the supervisor, such as "Can you ask your supervisor for help if necessary?" ( $1=$ never, $5=$ always; alphas were .88 (T0), .91 (T1), and .87 (T2)). Possibilities for professional development were measured using a four-item scale (Bakker et al., 2005), for instance, "My work offers me the opportunity to learn new things" $(1=$ strongly disagree to $5=$ strongly agree). The Cronbach's alpha coefficients were .87 (T0), .83 (T1), and .83 (T2).

Burnout was measured with five items of the Maslach Burnout Inventory (Schaufeli, Leiter, Maslach, \& Jackson, 1996) assessing Emotional Exhaustion, which is the core dimension of burnout (Heuven, Bakker, Schaufeli, \& Huisman, 2006; Schaufeli \& Van Dierendonck, 2000). A typical item is "I feel used up at the end of a workday" $(0=$ never, $6=$ always $)$, and alpha coefficients were .89 (T0), .91 (T1), and .84 (T2).

Work engagement. Work engagement was measured using six items of the shortened Utrecht Work Engagement Scale (UWES; Schaufeli, Bakker, \& Salanova, 2006) that tapped the two core dimensions of work engagement, dedication, and vigor (Llorens, Schaufeli, Bakker, \& Salanova, 2007) with three items each. Sample items for dedication and vigor are "I am enthusiastic about my job" and "When I get up in the morning, I feel like going to work" ( $1=$ never, $6=$ always). Cronbach's alphas were .92 (T0), .93 (T1), and $.93(\mathrm{~T} 2)$.

Psychological capital. PsyCap consists of the four personal resources self-efficacy, resilience, hope, and optimism. Resilience, hope, and optimism were assessed using the Dutch version (Vink, Ouweneel, \& Le Blanc, 2011) of the Psychological Capital questionnaire (Luthans et al., 2007). Each concept was measured with six items (e.g., for resilience: "I usually take stressful things at work in stride"; for hope: "Right now I see myself as being pretty successful at work"; and for optimism: "I always look on the bright side of things regarding my job"). Self-efficacy was measured with Vink et al. (2011)'s five-item adaptation of Schwarzer and Jerusalem's (1995) scale. An example item is "If there are problems at work, I know how to solve them." All items were assessed at the first data collection wave (T0) only, and were answered on a five-point rating scale $(1=$ strongly disagree to $5=$ strongly agree $), \alpha=.81$. Following Luthans et al. (2008), the scores on the items of each scale were first averaged. Then, the averages for the four subscales were averaged to arrive at an overall score for PsyCap. 


\section{Statistical analyses}

For Hypotheses 1a-3b, repeated measures multivariate analysis of variance (RM MANOVA) were conducted with Time (T0 vs. T1 vs. T2) as the independent factor. To test Hypotheses $1 \mathrm{a}$ and 1b, we conducted a RM MANOVA with the three job demands (mental demands, workload, and task ambiguity) as dependent variables. To test Hypotheses $2 \mathrm{a}$ and 2b, a RM MANOVA was employed with the four job resources (autonomy, supervisor support, coworker support, and possibilities for professional development) as dependent variables. For Hypothesis 3a, burnout was the dependent variable whereas Hypothesis $3 \mathrm{~b}$ focused on work engagement as the dependent variable. To test Hypotheses $4 \mathrm{a}$ and 4b, all of these analyses were repeated, now adding PsyCap as a covariate (MANCOVAs) to test whether the interaction between Psycap and Time was significant.

\section{Results}

\section{Correlations}

Correlations between the study variables are shown in Table 1 and appear to be as expected. Intercorrelations for the measures taken at T0, T1, and T2 are high, and burnout and work engagement were negatively correlated. Moreover, less favorable scores on the job demands related to higher scores on burnout, whereas the job resources related to lower scores on burnout. Mental demands and workload did not correlate with work engagement. Less task ambiguity was related to higher work engagement, as were the measures for social support and professional development.

PsyCap (measured at T0) correlated with all study variables, except for mental demands and workload. Thus, scoring higher on PsyCap at T0 related to perceiving or experiencing less task ambiguity, more autonomy, more social support from the supervisor and coworkers, more opportunities for professional development, less burnout, and more work engagement throughout the study.

There were no significant correlations between the NWW adoption variable and the study variables, except for two minor correlations with T2 Autonomy of .22 and with T1 Work engagement of .18. Thus, the extent to which employees adopted NWW was not substantially related to job demands, job resources, the outcome variables, and PsyCap.

\section{Repeated measures ANOVA's}

We conducted a repeated measures ANOVA to check whether NWW was higher at $\mathrm{T} 1$ and $\mathrm{T} 2$ than at $\mathrm{T} 0$. This proved to be the case, $F(2,124)=65.40, p<.001$, $\eta^{2}=.513$, see Table 2 for means and standard deviations of NWW at T0, T1, and 


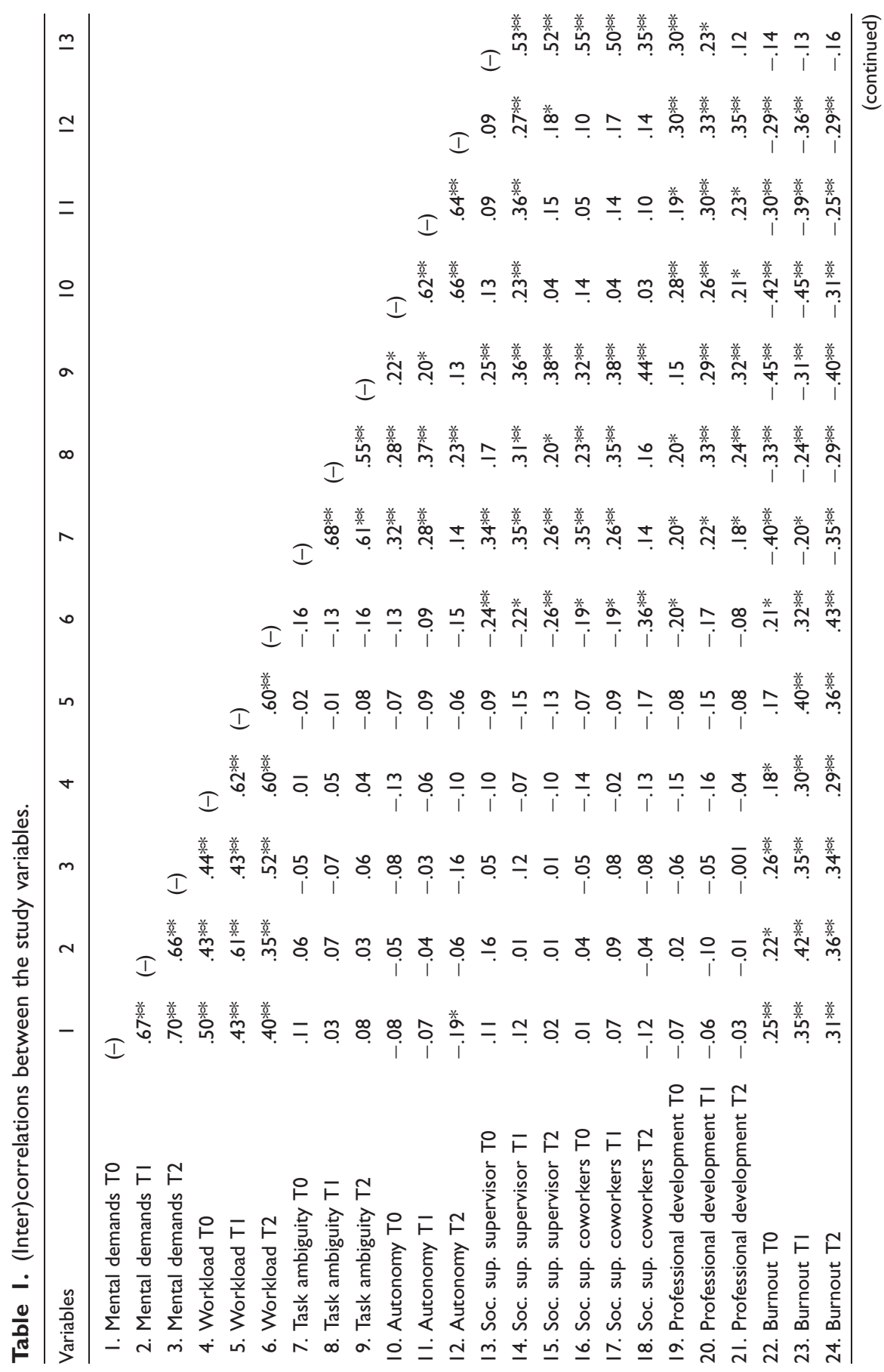




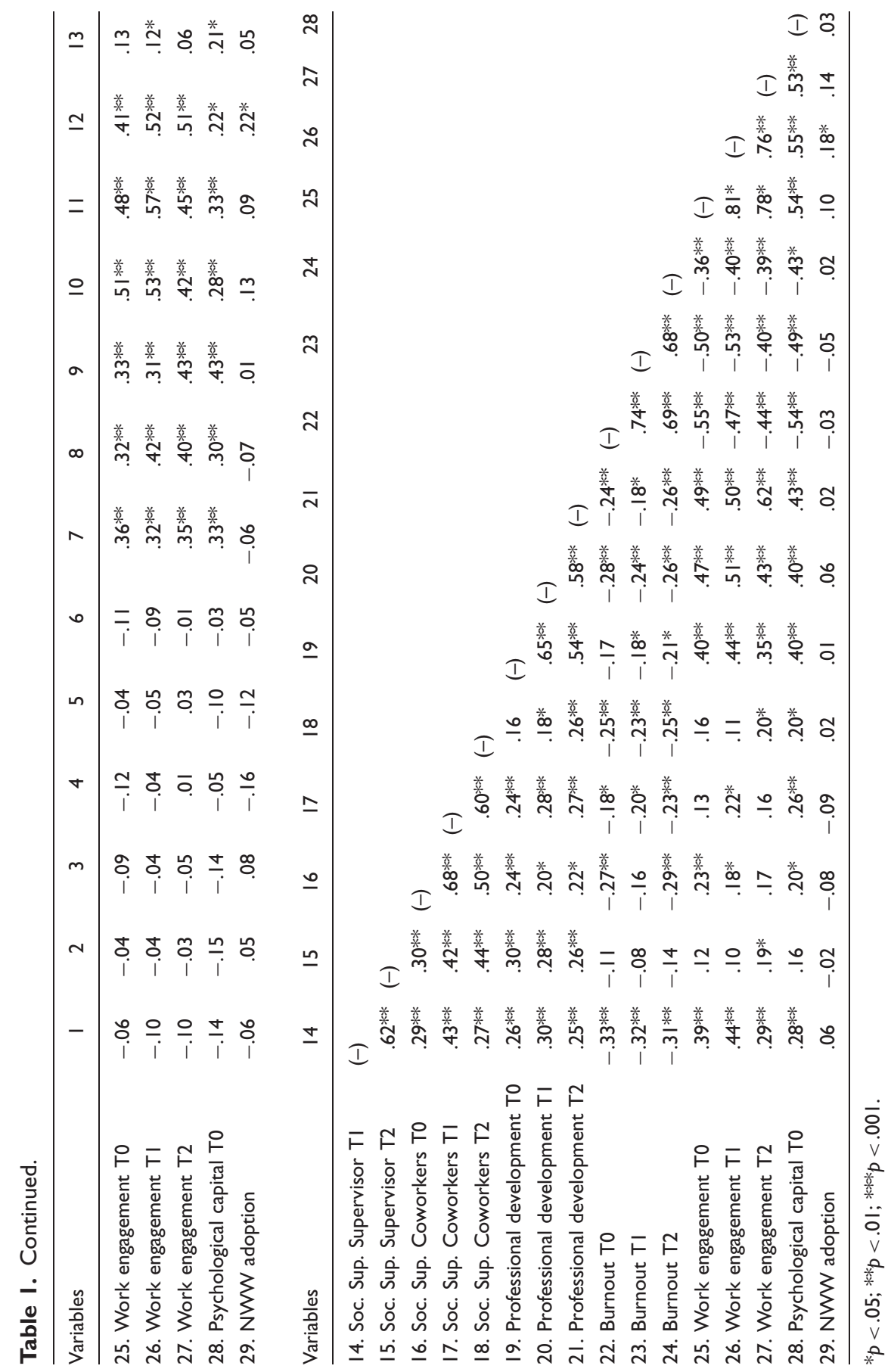


Table 2. Means and standard deviations for job demands, job resources, and individual outcomes.

\begin{tabular}{|c|c|c|c|c|c|c|}
\hline \multirow[b]{2}{*}{ Variables } & \multicolumn{2}{|c|}{ T0 } & \multicolumn{2}{|c|}{ TI } & \multicolumn{2}{|c|}{$\mathrm{T} 2$} \\
\hline & M & $S D$ & $M$ & $S D$ & M & $S D$ \\
\hline New ways of working & 3.80 & 1.30 & $5.02 * * * a$ & 1.60 & $5.06 * * * b$ & 1.52 \\
\hline Where and when I work & 3.57 & 1.90 & $4.21^{* * * a}$ & 2.02 & $4.11 * * * b$ & 2.07 \\
\hline IT use & 3.99 & 2.42 & $4.7 I^{* * * a}$ & 2.42 & $4.99 * * * b$ & 2.16 \\
\hline Working remotely & 3.91 & 2.16 & $4.25^{* a}$ & 2.23 & $4.3 I^{* b}$ & 2.10 \\
\hline Activity related working & 4.01 & 1.76 & $6.22 * * * a$ & 1.10 & $6.16 * * * b$ & 1.25 \\
\hline $\begin{array}{l}\text { Flex-desk concept } \\
\text { Job demands }\end{array}$ & 3.48 & 2.50 & $5.69 * * * a$ & 2.14 & $5.73 * * * b$ & 2.08 \\
\hline Mental demands & 3.51 & .59 & 3.56 & .68 & $3.38 * * b$ & .67 \\
\hline Workload & 3.18 & .79 & 3.16 & .84 & $3.05 * b$ & .84 \\
\hline Task ambiguity & 1.92 & .56 & 1.95 & .57 & 1.93 & .59 \\
\hline Job resources & & & & & & \\
\hline Autonomy & 3.56 & .75 & $3.44 * c$ & .82 & $3.42 *^{\mathrm{d}}$ & .82 \\
\hline Social support supervisor & 3.84 & .79 & 3.81 & .88 & 3.97 & .85 \\
\hline Social support coworkers & 4.14 & .68 & 4.16 & .68 & 4.16 & .76 \\
\hline $\begin{array}{l}\text { Possibilities for prof. development } \\
\text { Individual outcomes }\end{array}$ & 4.06 & .60 & 4.08 & .55 & $3.88 * * * b$ & .61 \\
\hline Burnout & 1.26 & .69 & 1.33 & .92 & 1.19 & .71 \\
\hline Work engagement & 4.19 & .91 & 4.17 & .95 & 4.20 & .93 \\
\hline
\end{tabular}

Note. Below the New Ways of Working measure, the values for the items of this measure are given.

a Mean difference over the short-term was significant in the expected/hypothesized direction.

bMean difference over the long-term was significant in the expected/hypothesized direction

'Mean difference over the short-term was significant, but not in the expected/hypothesized direction.

'Mean difference over the long-term was significant, but not in the expected/hypothesized direction.

$* p \leq .05 ; * * p \leq .01 ; * * * p \leq .001$.

T2. This also proved to be the case when inspecting the individual items of this measure, again see Table 2.

Please note that this study aimed to examine the effects of a transition to $N W W$ for the whole group of employees on their job demands, job resources, burnout, and work engagement. We therefore did not aim to include the extent to which employees adopted NWW. However, we did check whether including the NWW adoption variable $(M \mathrm{~T} 1, \mathrm{~T} 2-\mathrm{T} 0)$ as a covariate in the repeated measures analyses would change the results. This was not the case. This variable did not have a significant main effect or interaction effect with time and the results remained unchanged. Therefore, to preserve statistical power, we did not include this variable as a covariate in the results reported here. 
Job demands. We hypothesized that the transition, in both the short and the long term, would involve a decrease in mental demands and workload (Hypothesis 1a), and an increase in task ambiguity (Hypothesis $1 \mathrm{~b}$ ). To assess multicollinearity, correlations between the dependent variables were examined. No excessive correlations (all r's $<.60$ ) were found, indicating that multicollinearity was not a problem. Wilk's statistic showed a multivariate significant effect of Time on the combined job demands, $F(6,496)=2.99, p=.007, \eta^{2}=.035$. Mauchly's test of Sphericity showed that the assumption of sphericity was not violated. Univariate results revealed a significant effect of Time on mental demands, $F(2,250)=7.54$, $p=.001, \eta^{2}=.057$. As predicted, pairwise comparisons revealed that mental demands were significantly lower a year after the transition (T2) $(M=3.38$, $S D=.67)$ than at T0 $(M=3.51, S D=.59), 95 \%$ CI $[.04, .21], p<.01$. Further, we found a marginally significant effect of Time on workload, $F(2,250)=2.53$, $p=.082, \eta^{2}=.020$. Consistent with our expectations, pairwise comparisons indicated that workload was significantly lower a year after the transition (T2) $(M=3.05, S D=.84)$ than before the transition (T0) $(M=3.18, S D=.79)$, $95 \%$ CI $[.01, .27], p<.05$. Thus, Hypothesis 1a was partially supported in that a transition to NWW was associated with reductions in mental demands and workload, but only at the long term. However, the univariate results revealed no effect of Time on task ambiguity (Hypothesis $1 \mathrm{~b}$ not supported).

Job resources. In the same vein, we tested Hypotheses $2 \mathrm{a}$ and $2 \mathrm{~b}$ to examine short- and long-term effects of the transition on the job resources (autonomy, supervisor support, coworker support, and possibilities for professional development). Using Wilk's statistic, findings indicated that there was a significant effect of Time on the combined job resources, $F(8,494)=4.41, p<.001$, $\eta^{2}=.067$. Mauchly's test of Sphericity was significant for coworker support. Therefore, we used a Greenhouse-Geisser correction for the latter variable (Abdi, 2010; Greenhouse \& Geisser, 1959).

Hypothesis 2a stated that the transition to NWW would in both the short and the long term involve an increase in autonomy. The univariate results revealed a significant effect of Time on autonomy, $F(2,250)=3.21, p=.042, \eta^{2}=.025$. Unexpectedly, pairwise comparisons indicated that autonomy was significantly lower three months after the transition (T1) $(M=3.44, S D=.82), 95 \%$ CI $[.01$, .24], $p<.05$, and a year after the transition (T2) $(M=3.42, S D=.82), 95 \% \mathrm{CI}$ $[.03, .25], p<.05$, than before the transition (T0) $(M=3.56, S D=.75)$. Thus, Hypothesis 2a was not supported.

Hypothesis $2 \mathrm{~b}$ stated that a transition to NWW would in both the short and the long term involve a decrease in supervisor support, coworker support, and possibilities for professional development. The univariate results revealed no significant effects for supervisor support or coworker support. However, a significant effect on possibilities for professional development was found, $F(2$, $250)=10.65, p<.001, \eta^{2}=.078$. Consistent with our prediction, possibilities 
for professional development were significantly lower one year after the transition (T2) $(M=3.88, S D=.61)$ than before the transition (T0) $(M=4.06$, $S D=.60), 95 \%$ CI $[.07, .28], p<.001$. Thus, overall, there was limited support for Hypothesis $2 \mathrm{~b}$ in that, although the possibilities for professional development decreased over the long term, neither the predicted short-term effects on possibilities for professional development nor the predicted short- and long-term effects on coworker support were found.

Burnout and work engagement. A one-way repeated measures ANOVA was used to investigate short- (T0-T1) and long-term effects (T0-T2) of the transition to NWW on burnout (Hypothesis 3a). The results showed no significant effect of time on burnout. Similarly, a repeated measures ANOVA was used to investigate the short- and long-term effects of the transition on work engagement (Hypothesis 3b). No effect of time on work engagement was found (see Table 2). Summarizing, we did not find support for Hypothesis $3 a$ and $3 b$, which respectively predicted that burnout would decrease and work engagement would increase.

Psychological capital. Hypothesis 4a stated that the beneficial effects of the transition would be stronger for employees with higher levels of PsyCap than for employees with lower levels of PsyCap. Hypothesis $4 \mathrm{~b}$ stated that the adverse effects of the transition would be weaker for employees with higher PsyCap. To test these hypotheses, we conducted MANCOVAs, rerunning all repeated measures analyses above described, but now with PsyCap as a covariate. In none of the analyses, the Time $\times$ PsyCap interaction effect was significant (Hypotheses $4 \mathrm{a}$ and $4 \mathrm{~b}$ not supported). We did, however, find interesting main effects for PsyCap, which will be detailed below.

For job demands, Wilk's statistic showed a multivariate main effect for PsyCap, $F(3,122)=10.92, p<.001, \eta^{2}=.212$. Univariate results revealed that this main effect for PsyCap was significant for task ambiguity, $F(1,124)=25.67$, $p<.001, \eta^{2}=.172$, but not for the job demands workload and mental demands. The main effect for time was not significant anymore in this MANCOVA, whereas it was significant in the MANOVA described earlier.

For job resources, Wilk's statistic showed a multivariate main effect for PsyCap $F(4,121)=11.07, p<.001, \eta^{2}=.268$. Univariate results revealed that this main effect for PsyCap was significant for autonomy, $F(1$, $124)=14.07, p<.001, \eta^{2}=.101$, supervisor support, $F(1,124)=8.82, p<.01$, $\eta^{2}=.066$, coworker support, $F(1,124)=8.81, p<.01, \eta^{2}=.006$, as well as professional development, $F(1,124)=37.54, p<.001, \eta^{2}=.232$. However, the main effects for time found in the MANOVA described earlier were not significant anymore.

In the same vein, the ANCOVA for burnout revealed a significant main effect for PsyCap, $F(1,124)=51.91, p<.001, \eta^{2}=.295$. The ANCOVA for work 
engagement also revealed a significant main effect for PsyCap, $F(1,124)=64.04$, $p<.001, \eta^{2}=.341$.

In sum, PsyCap did not moderate the effects of the transition, but significant main effects of PsyCap were found for one of the job demands, namely task ambiguity, for all job resources, and for burnout and work engagement.

\section{Discussion}

This research aimed to address several important shortcomings of previous research on NWW by using the JD-R model (Bakker \& Demerouti, 2007) as a clear theoretical framework for investigating not only underlying mechanisms of the effects of NWW but also more distal outcomes. The main purpose of our study was to examine the short- and long-term effects of a mandatory transition to NWW on employees' job demands, job resources, burnout, and work engagement, in relation to their personal resources (PsyCap). A major strength of this study was its longitudinal design with one pre-transition, and two post-transition moments of measurement, whereas most previous studies examined NWW only after it had already been implemented. This study contributes to existing knowledge about the impact of NWW on employees by showing both beneficial and adverse effects on job characteristics.

\section{Beneficial and adverse effects of NWW}

Job demands. We found beneficial long-term effects of a transition to NWW on mental demands and workload. As hypothesized, this transition to NWW seemed to make working somewhat less demanding and less stressful for employees, at least at the longer term. This parallels earlier studies which demonstrated that NWW reduces time pressure, and increases feelings of flexibility, control, and efficient communication (Bailey \& Kurland, 2002; Mann et al., 2000; Sardeshmukh et al., 2012; Ten Brummelhuis et al., 2012). However, the predicted short-term effects on job demands were not found. This may be explained by the fact that it may have taken a while for employees to adjust the new working routines to their needs. We also expected an adverse effect of NWW on task ambiguity over the short and over the long term, but this was not the case. One explanation for this lack of an effect is that the transition to NWW had been well prepared in this specific organization and new work guidelines had been well documented and communicated.

Job resources. We predicted and found an adverse effect long-term effect of the transition to NWW on employees' perceptions of possibilities for professional development. This finding is in line with the notion that NWW reduces career development opportunities because of fewer learning opportunities (Cooper \& Kurland, 2002; Mann et al., 2000). Contrary to our expectations, we found an 
adverse effect of NWW on autonomy in that autonomy decreased over the short- and over the long-term. This finding is important and remarkable, because in the literature an increase in autonomy is often considered an important advantage of NWW (e.g., Gajendran \& Harrison, 2007). A possible explanation for this finding in the current study is that it concerned a mandatory transition. Although employees could still choose to work at the office instead of working at home, it was mandatory in the sense that employees did not have their own desk or office space anymore and were thus obliged to change their working routines, both of which might have reduced feelings of control. This is consistent with the arguments made by other scholars that mandatory telecommuting or NWW decreases autonomy, because it by definition reduces employees' freedom (Lapierre, Van Steenbergen, Peeters, \& Kluwer, 2015; Shamir \& Salomon, 1985). Additionally, the fact that employees were expected to follow new rules and guidelines after the transition may also have imposed constraints on their autonomy (Kavanagh \& Ashkanasy, 2006; Thatcher \& Zhu, 2006). Either way, it shows that a main aim of NWW-enhancing autonomy-was not realized via this transition. An interesting parallel here is the introduction of lean production in teams. Advocates argue that lean production transfers tasks and responsibilities to the workers, and engages them in problem solving which can be considered job enlargement and thus should reduce stress and enhance motivation (see Parker, 2003). Importantly, however, a longitudinal study on the effects of lean production demonstrated a decrease in autonomy three years later (Parker, 2003). Possibly also in this case, it was the mandatory nature of work redesign that decreased employees' autonomy.

Furthermore, we predicted an adverse effect on supervisor support over the short and long term, but found no significant changes over time. Interestingly, this parallels partly with Gajendran and Harrison's (2007), who also expected a negative relationship between telecommuting and the quality of the relationship with the supervisor but instead found a positive relationship. It is possible that supervisors were well aware of the potential pitfalls of NWW, and instead of having less contact, invested more time in maintaining a good relationship with workers. In addition, employees themselves may have informed their supervisor more about their work when working at different hours and places (cf. Gajendran \& Harrison, 2007).

In addition, we found that employees experienced the same level of coworker support as before the introduction of NWW. This is consistent with Gajendran and Harrison (2007) who found a nonsignificant overall relationship between telecommuting and coworker support. They found that this relationship was moderated by the time employees spent away from the office, in that only high-intensity telecommuting (defined as working remotely for 2.5 or more days per week) had a negative impact on the relationship with coworkers. After the transition in the current organization, supervisors informed us that the majority of the employees still worked the main part of their working hours 
at the office. In that sense, most participants in our sample could be considered low-intensity telecommuters.

Except for autonomy, we did not find support for our predictions that the transition to NWW would change job characteristics over the short term. It is likely that employees needed some time to adjust to the changes. However, as feelings of control may have been reduced from the beginning through the mandatory aspect of this transition, it is likely that this has negatively affected employees' experienced autonomy from the start.

Burnout and work engagement. This was one of the first studies to examine the consequences of NWW on burnout and work engagement (with the notable exceptions of Sardeshmukh et al., 2012; Ten Brummelhuis et al., 2012; Ter Hoeven et al., 2016). Contrary to our expectations, we did not find support for the notion that the transition would cause burnout to decrease and work engagement to increase over the short and/or long term. Although our findings were in line with the idea that a transition to NWW alters various job characteristics, the changes were relatively small. Therefore, it is perhaps not surprising that burnout and work engagement did not significantly change over time. A second possibility is that it may take longer for NWW to impact on burnout and work engagement than initially expected, since most job characteristics only changed at the long term as well. A third alternative explanation might be that NWW only translates into higher work engagement and lower burnout for workers who have voluntarily chosen this work modality (as was for instance the case in the study by Ten Brummelhuis et al., 2012, but not in general when NWW is mandatory (as was the case in the present study).

\section{Do NWW paradoxes really exist?}

Our findings indicate that NWW can simultaneously be beneficial (i.e., lead to a decrease in mental demands and workload) and detrimental (i.e., lead to decreases in autonomy and possibilities for professional development) for employees. In that sense, our data do support the idea that transitioning to NWW entails a paradox. Our findings based on three waves of data also suggest that these effects are relatively small, and emerge mainly over the long term. Moreover, the small changes over time we observed in job demands and job resources were not significant anymore when PsyCap was taken into account in the analyses, which had strong main effects. Possibly, with our relatively small $N$, there was not enough statistical power for the relatively weak effects of time to remain significant. Alternatively, high-PsyCap participants may adjust themselves sooner after the implementation of NWW than others, suppressing main or interaction effects involving Time. In either case, these findings do suggest that the effect of NWW on employees' job characteristics and work-related well-being may not be as substantial as previously thought. As such, the current 
empirical results give way to a critical view on NWW in that the NWW paradigm does not live up to its promises of increasing employee well-being. Rather, NWW may just be a managerial hype, and mainly a way to cut costs via limiting office space (e.g., Gorgievski, van der Voordt, Van Herpen, \& Van Akkeren, 2010; Noonan \& Glass, 2012)—which can be an organizational goal in its own right.

\section{Do employees with higher PsyCap make a better transition?}

In the last decade, various scholars have recommended taking individual difference variables into account, since differences between employees are expected to influence the impact of NWW on various outcomes (e.g., Sardeshmukh et al., 2012; Virick et al., 2010). However, the current study showed no evidence for a moderating role of PsyCap. Although Van den Heuvel et al. (2010) proposed that personal resources may play an important role in effectively coping with organizational change processes, employees' PsyCap did not alter the impact of NWW on employees' job demands, job resources, burnout, or work engagement. In that sense, employees with higher levels of PsyCap were not more capable of making the transition to NWW than others. These findings are in line with a previous study by Xanthopoulou, Bakker, Demerouti, and Schaufeli (2007) who also expected that personal resources (e.g., self-efficacy, optimism) would moderate the effects of work characteristics on outcomes, but who found no support for their hypotheses. They suggested that the moderating role may depend on the specific personal resources used, in that some may operate mainly at an affective-cognitive level (e.g., self-efficacy, optimism), whereas others are of a more behavioral-practical nature (e.g., time management skills) (Xanthopoulou et al., 2007, p. 136). More practical personal resources might have a greater effect on the way employees deal with specific job demands such as workload, thereby creating a difference between employees with more or less time-management skills (Peeters \& Rutte, 2005; Xanthopoulou et al., 2007). It is possible that the personal resource Psycap (consisting of self-efficacy, resilience, hope, and optimism) was not practical enough in nature to have a beneficial effect in the case of transitioning to NWW.

Although the present study did not focus on the direct effects of PsyCap on job characteristics and burnout and work engagement, our findings did demonstrate important main effects of PsyCap. That is, employees with higher levels of PsyCap perceived less task ambiguity, more autonomy, more supervisor support, more coworker support, more opportunities for professional development, had lower burnout levels, and had higher work engagement than employees with lower PsyCap at all three data waves. Thus, a high level of PsyCap may have important benefits for employees' outlook on their work and their burnout and work engagement levels. This is consistent with the finding that PsyCap predicts higher general employee well-being over time (Avey et al., 2010; Newman et al., 2014). 
As PsyCap is not a given, but can be trained to a certain extent (Luthans et al., 2006; Luthans et al., 2008), organizations could obtain important improvements by offering such trainings (see also Practical Implications section below).

These findings are consistent with previous studies showing that personal resources can influence the perception of job characteristics and can also directly impact employees burnout and work engagement (Schaufeli \& Taris, 2014). Thus, our study points to the relevance of investigating the exact role of personal resources in the JD-R model (see also Schaufeli \& Taris, 2014), as it may not only explain some of the differences in job characteristics between employees (e.g., perception of more or less job demands) but may also hold the key to greater employee well-being.

\section{Limitations and future research directions}

Several limitations of the present study should be acknowledged. First of all, we were unfortunately not able to collect data from a control group, as all employees of this unit transitioned to NWW at the same time, and there was no suitable control group. Therefore, we cannot be fully certain that the effects were caused by the transition to NWW instead of by general changes in the organization or in society as a whole. However, our approach of collecting three waves of data forms an important step in the right direction, since previous studies all were cross-sectional in nature. Second, this study aimed to examine the effects of $a$ transition to $N W W$ for the whole group of employees on their job demands, job resources, burnout, and work engagement. Therefore, this study did not assess the extent of NWW in a detailed manner (e.g., the number of days working from home per week, times working at irregular hours), although this can relate to several job characteristics, burnout, and work engagement (Sardeshmukh et al., 2012). Our measures of NWW at T0, T1, and T2 did however reveal that employees worked according to NWW to a significantly higher degree after the transition than before. Moreover, correcting for the extent to which individuals adopted NWW did not change the findings we reported here.

Third, we examined only one financial services organization in the Netherlands which implemented a mandatory transition to NWW. Therefore, our findings cannot be generalized to all other organizations and contexts. Finally, the number of participants in our sample was relatively small (the number of participants for whom full data were available was only 126). This necessarily imposed limits to the sort of analyses that could be conducted. For example, although it would have been interesting to test time-lagged structural equation models in which - say-burnout and work engagement at $\mathrm{T} 2$ would be examined as a function of demands and resources at T1 and T0, this type of analyses tend to require a considerably larger sample than was available for this study (Kline, 2011). We therefore restricted ourselves to conducting relatively simple, yet robust analysis of variance. 
Despite these limitations, we believe this study provides interesting directions for future longitudinal research on the effects of NWW, as it suggests that its effects on job characteristics are not straightforward. On the one hand, our findings have supported previous research (i.e., decrease in the job demands mental demands and workload, and a decrease in the job resource possibilities for professional development), but on the other hand, we have also found an unexpected result (i.e., decrease in autonomy). A challenging task for further longitudinal research is therefore not only to include a control group but also the specification of conditions under which the effects of NWW occur, thereby possible resolving the question whether a NWW paradox really exists. Besides potential differences in outcomes between mandatory and voluntary NWW, the way organizations design their NWW practices and the intensity of NWW may offer important avenues for future research. It is likely that some aspects of NWW (e.g., choosing your own work hours and location) cause more beneficial effects whereas others (e.g., losing your own desk, working in an open office space, new rules and guidelines, high-intensity NWW) may have negative effects on job characteristics and burnout and work engagement. Moreover, despite the fact that the way in which NWW was implemented in this organization is common for organizations in the Netherlands, differences in NWW practices may have a considerable impact on outcomes. It would therefore also be interesting to examine employees' perceptions of the change. For example, is the nature of the transition (mandatory vs. voluntary) also perceived as such by the employees? Do they consider it a positive change? And can these perceptions predict employees' job demands and resources later on? These issues underline the need for longitudinal research on NWW and the conditions under which its effects occur, if they occur.

Finally, in addition to PsyCap, other personality variables and personal resources should be examined. For example, Judge, Thoresen, Pucik, and Welbourne (1999) found that managers higher in Openness to experiences were better able to cope with organizational change. Moreover, practical personal resources such as flexibility (i.e., adapting to changes at work), proactivity (i.e., actively dealing with problems, and seizing opportunities, Xanthopoulou et al., 2007), and boundary management (i.e., segmenting work and family roles to foster focus on the task at hand) may enable employees to make an optimal transition to telecommuting (Lapierre et al., 2015).

\section{Practical implications}

The current study revealed some positive effects of a transition to NWW, but certainly not the big positive changes that organizations often (communicate) to strive for. It also revealed no effects or negative ones. On the positive side, these findings suggest that NWW can be somewhat beneficial in reducing mental demands and workload. In addition, these findings suggest that NWW does 
not need to hurt the employee-supervisor relationship or relationships between coworkers.

However, our findings also suggest that a transition to NWW has an adverse effect on possibilities for professional development. When top management decides to transition to NWW, it is therefore important to place professional development of employees prominently on the agenda, thereby reducing the risk of professional isolation. Human Resources could take the lead in developing a strategy for the professional development of new workers. Additionally, supervisors play a key role, for example, by discussing personal development with employees on a relatively frequent and regular basis. Importantly, our findings point in the direction of negative effects of mandatory NWW on autonomy as opposed to the positive impact of voluntary NWW on autonomy, which has been suggested in previous studies (e.g., Shamir \& Salomon, 1985; Thatcher \& $\mathrm{Zhu}, 2006)$. Organizations should therefore take these potential adverse consequences of mandatory NWW into consideration when making decisions about a transition to this new work modality. In addition, as the beneficial effects of NWW seem to be relatively small, organizations should carefully consider if a transition to NWW will bring the changes they strive for. As our results consistently show that employees with higher levels of PsyCap enjoy higher levels of well-being, and as PsyCap can be trained, organizations could consider providing PsyCap interventions as this might be a much more promising intervention to stimulate employees' well-being and support sustainable employability in general (e.g., Luthans et al., 2006).

Finally, in the case of a transition to NWW, it seems important for organizations to prepare and communicate a transition to NWW thoroughly. Open communication and employee participation in the change process are important success factors not only for a transition to NWW but also for change efforts in general (e.g., Weber \& Weber, 2001). When transitioning to NWW, it seems important to follow the current organization in ensuring a sufficient number of vacant desks and activity-related workspaces, instead of focusing on a reduction in real estate costs (e.g., Apgar, 1998) through NWW. Additionally, Human Resources can take an active role in stimulating both employees and supervisors to be proactive in NWW and invest extra time in maintaining good working relationships. Finally, monitoring the effects of NWW during the change process may enable organizations to counteract potential negative effects of NWW such as the decrease in possibilities for professional development, while at the same time heightening the beneficial effects.

\section{Conclusion}

An active debate is going on in the literature about the effects of NWW, in which advocates and opponents fuel the discussion with mostly cross-sectional studies. To our knowledge, this is the first study to provide longitudinal evidence for 
favorable as well as adverse consequences of NWW on job characteristics, thereby supporting the idea that the introduction of NWW can entail a paradox for organizations. However, this study also points out that the effects are relatively small. On the one hand, our findings suggest that a transition to NWW can decrease mental demands and workload. On the other hand, all that glitters certainly is not gold, in that a transition to NWW seems to harm career opportunities over the longer run, and mandatory NWW is likely to negatively impact employee autonomy. Further longitudinal research is needed to gain more insight in the conditions under which the effects of NWW occur, and the exact role of various personal resources in the process.

\section{Author Note}

Cilia van der Ven wrote her Master thesis on the data set here presented.

\section{Declaration of Conflicting Interests}

The author(s) declared no potential conflicts of interest with respect to the research, authorship, and/or publication of this article.

\section{Funding}

The author(s) received no financial support for the research, authorship, and/or publication of this article.

\section{References}

Abdi, H. (2010). The Greenhouse-Geisser correction. In N. Salkind (Ed.), Encyclopedia of research design (pp. 1-10). Thousand Oaks, CA: Sage.

Apgar, M. (1998). The alternative workplace: Changing where and how people work. Harvard Business Review, 76, 121-136.

Avey, J. B., Luthans, F., Smith, R. M., \& Palmer, N. F. (2010). Impact of psychological capital on employee well-being over time. Journal of Occupational Health Psychology, $15,17-28$.

Baarne, R., Houtkamp, P., \& Knotter, M. (2010). Het nieuwe werken ontrafeld [Unraveling new ways of working]. Assen, The Netherlands: Koninklijke Van Gorcum/Stichting Management Studies.

Bakker, A. B., \& Demerouti, E. (2007). The Job Demands-Resources model: State of the art. Journal of Managerial Psychology, 22, 309-328.

Bakker, A. B., Demerouti, E., \& Euwema, M. C. (2005). Job resources buffer the impact of job demands on burnout. Journal of Occupational Health Psychology, 10, 170-180.

Bakker, A. B., Demerouti, E., Taris, T., Schaufeli, W. B., \& Schreurs, P. (2003). A multigroup analysis of the Job Demands-Resources model in four home care organizations. International Journal of Stress Management, 10, 16-38.

Bakker, A. B., Demerouti, E., \& Verbeke, W. (2004). Using the Job Demands-Resources model to predict burnout and performance. Human Resource Management, 43, 83-104. 
Bailey, D. E., \& Kurland, N. B. (2002). A review of telework research: Findings, new directions, and lessons for the study of modern work. Journal of Organizational Behavior, 23, 383-400.

De Bloom, J., Kompier, M. A. J., Geurts, S. A. E., Taris, T., \& Sonnentag, S. (2009). Do we recover from vacation? Meta-analysis of vacation effects on health and well-being. Journal of Occupational Health, 51, 13-25.

Brownson, K. (2004). The benefits of a work-at-home program. Health Care Manager, 23, 141-144.

Cooper, C. D., \& Kurland, N. B. (2002). Telecommuting, professional isolation and employee development in public and private organizations. Journal of Organization Behavior, 23, 511-532.

Daft, R. L., \& Lengel, R. H. (1986). Organizational information requirements, media richness and structural design. Management Science, 32, 554-571.

DeCharms, R. (1968). Personal causation: The internal affective determinants of behavior. New York, NY: Academic Press.

Demerouti, E., Bakker, A. B., Nachreiner, F., \& Schaufeli, W. B. (2001). The job demands-resources model of burnout. Journal of Applied Psychology, 86, 499-512.

Demerouti, E., Derks, D., Ten Brummelhuis, L. L., \& Bakker, A. B. (2014). New ways of working: Impact on working conditions, work-family balance, and well-being. In C. Korunka \& P. Hoonakker (Eds.), The impact of ICT on quality of working life (pp. 123-141). Dordrecht, The Netherlands: Springer.

Furda, J. (1995). Werk, persoon en welzijn: Een toets van het JD-C model [Work, personality, and well-being: A test of the JD-C model]. Unpublished doctoral dissertation, Utrecht University, Utrecht, The Netherlands.

Gajendran, R. S., \& Harrison, D. A. (2007). The good, the bad, and the unknown about telecommuting: Meta-analysis of psychological mediators and individual consequences. Journal of Applied Psychology, 92, 1524-1541.

Golden, T. D. (2006). The role of relationships in understanding telecommuter satisfaction. Journal of Organizational Behavior, 27, 319-340.

Golden, T. D., Veiga, J. F., \& Dino, R. N. (2008). The impact of professional isolation on teleworkers job performance and turnover intentions: Does time spent teleworking, interacting face-to-face time, or having access to communication-enhancing technology matter?. Journal of Applied Psychology, 93, 1412-1421.

Golden, T. D., Veiga, J. F., \& Simsek, Z. (2006). Telecommuting's differential impact on work-family conflict: Is there no place like home? Journal of Applied Psychology, 91, 1340-1350.

Gorgievski, M. J., van der Voordt, T. J. M., Van Herpen, S. G. A., \& van Akkeren, S. (2010). After the fire: New ways of working in an academic setting. Facilities, 28(3/4), 206-224. Retrieved from https://doi.org/10.1108/02632771011023159

Greenhouse, S. W., \& Geisser, S. (1959). On methods in the analysis of profile data. Psychometrika, 24, 95-112.

Hackman, J. R., Pearce, J. L., \& Wolfe, J. C. (1978). Effects of changes in job characteristics on work attitudes and behaviors: A naturally occurring quasi-experiment. Organizational Behavior and Human Performance, 21, 289-304.

Heuven, E., Bakker, A. B., Schaufeli, W. B., \& Huisman, N. (2006). The role of self-efficacy in performing emotion work. Journal of Vocational Behavior, 69, 222-235. 
Judge, T. A., Thoresen, C. J., Pucik, V., \& Welbourne, T. M. (1999). Managerial coping with organizational change: A dispositional perspective. Journal of Applied Psychology, 84(1), 107.

Karasek, R. (1985). Job content instrument: Questionnaire and user's guide, revision 1.1. Los Angeles: University of Southern California.

Kavanagh, M. H., \& Ashkanasy, N. M. (2006). The impact of leadership and change management strategy on organizational culture and individual acceptance of change during a merger. British Journal of Management, 17, 81-103.

Kelliher, C., \& Anderson, D. (2008). For better or for worse? Analysis of how flexible working practices influence employees perceptions of job quality. The International Journal of Human Resource Management, 19, 419-431.

Kline, R. B. (2011). Principles and practice of structural equation modeling (3rd ed.). New York, NY: Guildford Press.

Korver, T. (2006). The new employee: An elusive concept. In B. van Hees \& P. Verweel (Eds.), Deframing organizational concepts (pp. 221-266). Rosenoerns, Denmark: CBS Press.

Lapierre, L. M., Van Steenbergen, E. F., Peeters, M. C. W., \& Kluwer, E. S. (2015). Juggling work and family responsibilities when involuntarily working more from home: A multiwave study of financial sales professionals. Journal of Organizational Behavior, 37, 804-822.

Llorens, S., Schaufeli, W. B., Bakker, A. B., \& Salanova, M. (2007). Does a positive gain spiral of resources, efficacy beliefs and engagement exist? Computers in Human Behavior, 23, 825-841.

Luthans, F., Avey, J. B., Avolio, B. J., Norman, S. M., \& Combs, G. M. (2006). Psychological capital development: Toward a micro-intervention. Journal of Organizational Behavior, 27, 387-393.

Luthans, F., Avey, J. B., \& Patera, J. M. (2008). Experimental analysis of a web-based training intervention to develop positive psychological capital. Academy of Management Learning \& Education, 7, 209-221.

Luthans, F., Avolio, B. J., Avey, J. B., \& Norman, S. M. (2007). Positive psychological capital: Measurement and relationship with performance and satisfaction. Personnel Psychology, 60, 541-572.

Luthans, F., Norman, S. M., Avolio, B. J., \& Avey, J. B. (2008). The mediating role of psychological capital in the supportive organizational climate - employee performance relationship. Journal of Organizational Behavior, 29, 219-238.

Mann, S., \& Holdsworth, L. (2003). The psychological impact of teleworking: Stress, emotions and health. New Technology, Work, and Employment, 18, 196-211.

Mann, S., Varey, R., \& Button, W. (2000). An exploration of the emotional impact of tele-working via computer-mediated communication. Journal of Managerial Psychology, 15, 668-690.

Montreuil, S., \& Lippel, K. (2003). Telework and occupational health: A Quebec empirical study and regulatory implications. Safety Science, 41, 339-358.

Newman, A., Ucbasaran, D., Zhu, F., \& Hirst, G. (2014). Psychological capital: A review and synthesis. Journal of Organizational Behavior, 35, 120-138.

Noonan, M. C., \& Glass, J. L. (2012). The hard truth about telecommuting. Monthly Labor Review, 6, 38-45.

Parker, S. K. (2003). Longitudinal effects of lean production on employee outcomes and the mediating role of work characteristics. Journal of Applied Psychology, 88, 620-634. 
Peeters, M. A. G., \& Rutte, C. G. (2005). Time management behavior as a moderator for the Job demand-control interaction. Journal of Occupational Health Psychology, 10, 64-75.

Peters, P., Poutsma, E., Van der Heijden, B. I. J. M., Bakker, A. B., \& De Bruijn, T. (2014). Enjoying new ways to work: An HRM-process approach to study flow. Human Resource Management, 53, 271-290.

Salanova, M., Agut, S., \& Peiró, J. M. (2005). Linking organizational resources and work engagement to employee performance and customer loyalty: The mediation of service climate. Journal of Applied Psychology, 90, 1217-1227.

Sardeshmukh, S. R., Sharma, D., \& Golden, T. D. (2012). Impact of telework on exhaustion and job engagement: A job demands and resources model. New Technology, Work and Employment, 27, 193-207.

Schaufeli, W. B., \& Bakker, A. B. (2004). Job demands, job resources, and their relationship with burnout and engagement: A multi-sample study. Journal of Organizational Behavior, 25, 293-315.

Schaufeli, W. B., Bakker, A. B., \& Salanova, M. (2006). The measurement of work engagement with a short questionnaire: A cross-national study. Educational and Psychological Measurement, 66, 701-716.

Schaufeli, W. B., Bakker, A. B., \& Van Rhenen, W. (2009). How changes in job demands and resources predict burnout, work engagement, and sickness absenteeism. Journal of Organizational Behavior, 30, 893-917.

Schaufeli, W. B., Leiter, M. P., Maslach, C., \& Jackson, S. E. (1996). Maslach Burnout Inventory-General Survey. In C. Maslach, S. E. Jackson \& M. P. Leiter (Eds.), The Maslach Burnout Inventory: Test manual (3rd ed., pp. 22-26). Palo Alto, CA: Consulting Psychologists Press.

Schaufeli, W. B., \& Taris, T. W. (2014). A critical review of the Job Demands-Resources Model: Implications for improving work and health. In G. F. Bauer \& O. Hämmig (Eds.), Bridging occupational, organizational and public health (pp. 43-68). Amsterdam, The Netherlands: Springer.

Schaufeli, W. B., \& Van Dierendonck, D. (2000). Handleiding van de Utrechtse Burnout Schaal (UBOS) [Manual of the Utrecht Burnout Scale]. Lisse, The Netherlands: Swets Test Services.

Schwarzer, R., \& Jerusalem, M. (1995). Generalized self-efficacy scale. In J. Weinman, S. Wright \& M. Johnston (Eds.), Measures in health psychology: A user's portfolio. causal and control beliefs (pp. 35-37). Windsor, England: NFER-NELSON.

Shamir, B., \& Salomon, I. (1985). Work-at-home and the quality of working life. Academy of Management Review, 10, 455-464.

Taris, T. W. (2000). A primer in longitudinal data analysis. London, England: Sage.

Taris, T. W., De Lange, A. H., \& Kompier, M. A. J. (2010). Research methods in occupational health psychology. In S. Leka \& J. Houdmont (Eds.), Occupational health psychology (pp. 269-297). Malden, MA: Wiley-Blackwell.

Ten Brummelhuis, L. L., Bakker, A. B., Hetland, J., \& Keulemans, L. (2012). Do new ways of working foster work engagement? Psicothema, 24, 113-120.

Ter Hoeven, C. L., van Zoonen, W., \& Fonner, K. L. (2016). The practical paradox of technology: The influence of communication technology use on employee burnout and engagement. Communication Monographs, 83(2), 239-263. 
Thatcher, S. M. B., \& Zhu, X. (2006). Changing identities in a changing workplace: Identification, identity enactment, self-verification, and telecommuting. Academy of Management Review, 31, 1076-1088.

Van den Heuvel, M., Demerouti, E., Bakker, A. B., \& Schaufeli, W. B. (2010). Personal resources and work engagement in the face of change. In J. Houdmont \& S. Leka (Eds.), Contemporary occupational health psychology: Global perspectives on research and practice (pp. 124-150). Chichester, England: John Wiley \& Sons Ltd.

Van Veldhoven, M., \& Meijman, T. F. (1994). Het meten van psychosociale arbeidsbelasting met een vragenlijst: de vragenlijst beleving en beoordeling van de arbeid (VBBA) [Measuring psychosocial pressure from work using a survey: The survey for rating work]. Amsterdam: NIA.

Van Yperen, N. W., \& Snijders, T. A. B. (2000). A multilevel analysis of the demandscontrol model: Is stress at work determined by factors at the group level or the individual level? Journal of Occupational Health Psychology, 5, 182-190.

Vink, J., Ouweneel, E., \& Le Blanc, P. (2011). Psychologische energiebronnen voor bevlogen werknemers: Psychologisch kapitaal in het Job Demands-Resources model [Psychological resources for engaged workers: Psychological capital in the Job Demands-Resources model]. Gedrag \& Organisatie, 24, 101-120.

Virick, M., DaSilva, N., \& Arrington, K. (2010). Moderators of the curvilinear relation between extent of telecommuting and job and life satisfaction: The role of performance outcome orientation and worker type. Human Relations, 63, 137-154.

Weber, P. S., \& Weber, J. E. (2001). Changes in employee perceptions during organizational change. Leadership \& Organization Development Journal, 22(6), 291-300. Retrieved from https://doi.org/10.1108/01437730110403222

Wright, T. A., \& Bonett, D. G. (1997). The contribution of burnout to work performance. Journal of Organizational Behavior, 18, 491-499.

Xanthopoulou, D., Bakker, A. B., Demerouti, E., \& Schaufeli, W. B. (2007). The role of personal resources in the Job Demands-Resources Model. International Journal of Stress Management, 14, 121-141.

\section{Author Biographies}

Elianne van Steenbergen works as an assistant professor in Social, Health, \& Organizational psychology at Utrecht University, for two days per week. Her research focuses on Work-life balance, New Ways of Working, and on Ethics and Morality at work. She also works at the Dutch Authority for Financial Markets (AFM) as a senior supervisor in the Behavior \& Culture team for two days per week.

Cilia van de Ven received her Master's degree (cum laude) in Social, Health, \& Organizational psychology from Utrecht University and now works in the Human Resources department at Ikea in the Netherlands. 
Maria Peeters works as an associate professor in Social, Health, \& Organizational psychology at Utrecht University. Her research focuses on the relationship between work and well-being. She is specifically interested in work engagement, workaholism, diversity, and job crafting.

Toon Taris is a full professor in Work \& Organizational psychology at Utrecht University, Department of Social, Health, \& Organizational Psychology. He teaches and conducts research in the area of well-being, motivation, and work performance. His main topics are occupational health psychology, burnout, work addiction, stress, engagement, authenticity at work, and work performance. 